https://helda.helsinki.fi

Developmental outcomes of children in classes for special educational needs : Results from a longitudinal study

\title{
Törmänen, Minna
}

2018-04

Törmänen , M \& Roebers , C M 2018 , ' Developmental outcomes of children in classes for special educational needs : Results from a longitudinal study ', Journal of Research in Special Educational Needs , vol. 18 , no. 2 , pp. 83-93 . https://doi.org/10.1111/1471-3802.12395

http://hdl.handle.net/10138/327837

https://doi.org/10.1111/1471-3802.12395

acceptedVersion

Downloaded from Helda, University of Helsinki institutional repository.

This is an electronic reprint of the original article.

This reprint may differ from the original in pagination and typographic detail.

Please cite the original version. 


\title{
Developmental outcomes of children in classes for special educational needs: results from a longitudinal study
}

\author{
Minna R.K. Törmänen ${ }^{1}$ and Claudia M. Roebers ${ }^{2}$ \\ ${ }^{1}$ University of Helsinki, Finland; ${ }^{2}$ University of Bern, Switzerland
}

Key words: Executive functions, cognitive control, academic achievements, socio-emotional skills, special education, inclusion.

\begin{abstract}
This longitudinal study investigates the differences in cognitive and socio-emotional development and academic achievement between children educated in special education classes $(N=37)$ and regular classes ( $N=37$ ). The study is retrospective. The first measurement point was while children were attending play-oriented kindergarten and no decision about their education had yet been made. The second measurement point followed after 2 years of schooling. Comparing carefully matched groups, no differences in executive functions (EFs) were found before beginning school. Children assigned to special education had poorer language, fine motor skills and a lower pre-academic self-concept, self-regulatory skills and social integration. Notably, every fourth child in special education was an immigrant, $9 \%$ of whom later attended regular classes. After 2 years of schooling in either setting, the groups differed significantly in academic achievement, EFs, fine motor skills and cognitive self-regulatory skills. However, it was not - as school officials had intended - that children in special education classes had caught up, except in regard to their academic self-concept and social integration.
\end{abstract}

Special educational needs and inclusive education Inclusive education is a key policy objective for children with special educational needs (SEN), but there is a question as to what degree schools are really adapting inclusive education. Research on background factors related to learning difficulties and the importance of executive functions (EF) as a powerful predictor of cognitive developmental outcomes and school achievement have received considerable attention.

Evaluating and conceptualising differences between children and their particular differences related to special needs and disability is a complex educational challenge. Much research has been dedicated to how special needs and learning difficulties are defined. There are a number of different theoretical approaches to SEN; however, classification of children's difficulties in learning into categories has played a key role in the history of special education (Terzi, 2005). One important question surrounds whether or not to identify children's differences, and if so, which differences are relevant to special education.

From one point of view, disabilities and special needs can be seen as being caused by an individual's limitations and deficits (e.g., Terzi, 2005). Others believe that special needs are caused by the limitations of the schooling system (Norwich, 2006). A crucial factor concerns the use of educational classification systems in relation to the role of children with disabilities.

The Salamanca World Conference on special needs education resulted in a document endorsing the idea of inclusive education (UNESCO, 1994). According to Ainscow (2005), this is the most significant international document in the special needs field. The use of inclusive education is a powerful way to combat discriminatory attitudes, leading to education for all and helping to build an inclusive society.

However, the realisation of inclusion is a major challenge for school systems throughout the world. Inclusive education is often thought of as an approach to serve children with disabilities within general education settings (Ainscow, 2005). Inclusive settings offer diverse education, taking into account every child's unique developmental and educational challenges. However, inclusion does not only refer to providing an educational support system for children with SEN; it is increasingly seen more broadly as a reform that supports and welcomes diversity amongst all learners, based on the notion that education is a basic human right and the foundation of a more equal society (e.g., Ainscow and Miles, 2009). Thus, inclusive schools are not established primarily for improving the learning and development of children with SEN. Specifically, inclusion aims to benefit children through improvements in 
their learning outcomes, including their social skills, academic achievement and personal development. To meet all the learning needs of the children, inclusion dictates a restructuring of mainstream schools (e.g., Wang, 2009).

Unfortunately, there is no consistent empirical evidence regarding the effects of inclusion. Even so, inclusive education should be promoted on two bases: the rights of children to be included in general education and the proposition that inclusive education is effective. Positive findings for inclusion related to academic achievements have been reported in some studies (e.g., Markussen, 2004). Inclusion in early education has been shown to positively affect social development (Buysse, Goldman and Skinner, 2002). In a study of pre-school children with SEN receiving education either in segregative or inclusive settings, the children in inclusive classes demonstrated higher levels of cognitive functioning (Rafferty, Piscitelli and Boettcher, 2003). Rea, McLaughlin and Walther-Thomas (2002) compared children with learning disabilities. They found that the group receiving inclusive education showed significantly higher academic achievements. A positive finding for inclusion was also reported by Markussen (2004), who compared children with SEN in different settings: the children with SEN in special education classes achieved a lower level of academic success compared with those in general education classes.

In contrast, studies in social participation among children with SEN offer another, less positive view on inclusion. Regarding acceptance by classmates, several studies showed that children with SEN felt less socially integrated and were more often segregated. Children with SEN also had fewer friends and displayed more loneliness (e.g., Schwab, Gebhardt, Krammera, et al., 2014).

Taken together, the empirical evidence concerning the advantages and disadvantages of educating children with SEN in regular classes is still inconsistent. Understanding this issue is important for developing evidence-based practices. In schools, children who don`t meet age-appropriate expectations for behavioural, emotional and/or cognitive self-regulation generate concern (Gilliam and Shahar, 2006). In general, the rate of special education referral is on the rise though the aim is to provide inclusive education. The purpose of this study was to examine children's cognitive development and academic achievements in two different educational settings.

\section{Cognitive control and school readiness}

In the context of children's school readiness and early self-regulatory skills, both contemporary discussions and empirical evidence emphasise the importance of EFs. Indeed, Blair and Raver (2015) proposed a multi-level model of school readiness, including biological, neurodevelopmental, emotional and cognitive aspects of a child's development, as being important for a successful transition into formal learning.
Executive functions are generally agreed to be subsumed under the umbrella of self-regulatory skills. Individual differences in EFs have consistent and substantial implications for everyday lives (Moffitt, Arseneault, Belsky, et al., 2011). Although there is no generally accepted definition of EFs, most researchers would agree that they encompass a variety of higher-order cognitive processes controlling and modulating cognition under continuously changing and multiple task demands (Hughes and Graham, 2002). In the present study, the term EF refers primarily to working memory (WM), which is usually defined as the capacity to retrieve information from longterm memory as well as the mental manipulation and adaptation of that information (Welsh, Nix, Blair, et al., 2010); inhibition refers to the capacity to ignore irrelevant stimuli and to inhibit automated or prepotent responses (Huizinga, Dolan and van der Molen, 2006); and cognitive flexibility involves shifting attention between different task demands, operations and mental sets (Diamond, 2006).

Executive functions are widely recognised to play an essential role in children's cognitive, social and motor development, and they have also been shown to significantly predict later school success. Moreover, they have repeatedly been found to be associated with the development of competencies in early childhood, ranging from self-regulation (e.g., Blair, 2002) to attention (Klenberg, Korkman and Lahti-Nuuttila, 2001). Research from early childhood suggests that these processes have a substantial impact on children's development of 'approaches to learning', learning outcomes in early elementary school years and learning-related behaviours in the classroom (e.g., Neuenschwander, Cimeli, Röthlisberger, et al., 2012).

While EF are substantially linked to early school achievement they also undergo a significant developmental trajectory during the ages of 5-7 years. These improvements seem to be due to maturation of the involved neural circuits including the prefrontal cortex (Diamond, 2013), but schooling or the change from mostly play-oriented learning to formal learning also affects developmental changes in EF (e.g., Welsh, Nix, Blair, et al., 2010). Of special importance for the present study, EF has repeatedly been found to serve as a powerful predictor of school readiness and school achievement (e.g., Blair and Raver, 2015).

In summary, EF are observable and measureable early in development and continue to improve into adolescence (e.g., Best and Miller, 2010). During the elementary school years, a further progression in EF is typically found. According to Lyons and Zelazo (2011), children become increasingly capable of integrating different mental representations, allowing a more accurate self-awareness of their performance as well as increasingly flexible adjustments in their responses. This shows not only in children's ability to adjust their information processing but also in their selfconcept (Roebers, Cimeli, Röthlisberger, et al., 2012). 


\section{Cognitive and socio-emotional self-regulation in children with SEN}

The processes involved in self-regulation can be divided into two broad classes: social-emotional and cognitive selfregulation (Liebermann, Giesbrecht and Muller, 2007). The former makes it possible for children to conform to social rules and to benefit in various social contexts while the latter allows children to use cognitive processes necessary for problem solving and related abilities. In general, the multidimensional construct of self-regulation includes processes that are involved in the regulation of emotions, motivation, cognition, social interactions and physical behaviour. Selfregulation in educational settings not only focuses on cognitive processes but also implies motivational and emotional self-regulatory processes that are manifested in social interactions. Importantly, emotion regulation and self-concept have been found to be predictors for school readiness (e.g., Blair and Raver, 2015). In addition, self-regulation is considered to be a central and significant developmental hallmark of the early childhood period as well as an important predictor of resilience in at-risk children (Buckner, Mezzacappa and Beardslee, 2003).

In the presence of otherwise normal cognitive functioning, deficits in these areas may contribute to learning disorders (Riggs, Blair and Greenberg, 2003). Further, deficits in EF include a range of impairments that have the capacity to interfere with effective adaptation to changing developmental demands for behavioural regulation as well as the achievement of social and cognitive competency.

Children with learning difficulties and mathematics learning difficulties show deficits in WM (D'Amico and Passolunghi, 2009). Measurements of WM also indicate the severity of learning disability (Henry, 2001). In summary, when studying children with SEN, it is important to explore EF and their impact on academic success. This leads to a demand for educational actions; if we are aware that poor development of EF is a risk factor, then educators and other professionals are obligated to offer early interventions.

In the early school years, children's academic self-concept is only loosely related to their academic performance (e.g., Spinath and Spinath, 2005). While the social selfconcept of children around the transition to school typically decreases slightly, their academic self-perceptions tend to further increase due to the newly acquired skills in school (e.g., Aunola, Leskinen, Onatsu-Arvilommi, et al., 2002) It has been argued that this self-serving bias plays a protective role by keeping children's motivation high despite failures (Bjorklund and Bering, 2002). It is further assumed that through experiences with one's factual competencies, this self-protective factor develops into a still positive but somewhat more realistic self-perception. This increasingly more realistic self-perception is known to positively influence academic outcomes, both in the short- and long run (Guay, Marsh and Boivin, 2003).

Recognising the mechanisms of mutual functioning of the teacher on a student's self-concept and achievement is important for successfully integrating children with SEN. Factors that appear to influence the self-concept of children with SEN include: the severity of disability, age of onset of disability, acceptance of the disability by parents, type of schooling and special support, labelling and identification group adherence (e.g., Schmidt and Čagran, 2008). Therefore, we expect that special education classes support the positive development of academic achievement as well as children's self-concepts.

The present longitudinal study, which is based on retrospective data, aimed at investigating possible differences in cognitive development, academic achievement and socio-emotional skills between children educated in two different educational settings: special education classes and regular classes.

\section{Description of special education classes in Switzerland} In Switzerland, children begin their school careers at the age of 5 in a 2-year long Kindergarten; first grade at elementary school begins at the age of seven. Whether students are placed in special education classes from the beginning of their school experience varies greatly in the Swiss context. After recognising that a child has SEN, teachers assign him or her to special education classes during the transition from Kindergarten to school. In most cases, children do not receive diagnoses, which follows the modern ideology of Response to Intervention (Fuchs and Fuchs, 2006). Children with many kinds of difficulties are assigned to special education classes. In addition to learning and academic difficulties and language, behavioural and attention problems, delays in general school readiness or postponed school entrance are reasons a child is assigned to a special education class.

Special education classes follow two different principles. First, the curriculum is adjustable and sometimes customised. For example, the first-grade curriculum is divided over two academic years. Second, class size is limited to 15 students. However, in our study, the mean special education class size was 12 pupils, compared to a mean class size of 18 pupils in regular classes. Teaching in the classrooms didn't involve the use of co-teaching methods, and there was usually one class teacher. Occasionally, a special educator provided additional support.

The children were selected for special education classes according to teachers' evaluation based on the children's overall performance in Kindergarten. The placement in special education was intended to support the pupils' individual learning with an adapted curriculum and special education. 


\section{Methods}

\section{Participants}

The children included in the analyses of this study were selected from a large data set $(\mathrm{N}=469)$ and used to investigate both typical and atypical development during the transition to school. The present study $(\mathrm{N}=74)$ focused on the development of children in special education classes $(\mathrm{N}=37$; mean age 74.6 months, $\mathrm{SD}=5.0$; range 63-86 months; 22 boys, 59.5\%). A comparable control group consisted of children from regular classes $(\mathrm{N}=37$; mean age 74.5 months, $\mathrm{SD}=4.8$; range 64 85 months; 22 boys, $59.5 \%$ ). The background variables for matching the groups were gender distribution, age and non-verbal intelligence.

The sample was recruited from German speaking cantons in Switzerland by contacting schools and kindergartens. The study population was drawn from 47 classes distributed across 24 school areas in different urban and rural regions. All parents provided informed consent. Parent educational level and the percentage of children with a migration background were representative of the target population. It was verified that all children were able to speak the official language with sufficient fluency. For about $70 \%$ of the children, Swiss German was their first language, which is representative of Switzerland.

\section{Procedure and materials}

\section{Design}

The data presented here originate from a 3-year longitudinal study with a cohort-sequence design. Two cohorts of children were recruited (5 and 6 year olds) and tested on cognitive EF with various measurements; questionnaires for teachers and parents were also used. During 3 consecutive years, the entire sample $(\mathrm{N}=469)$ was tested annually.

\section{Procedure}

Children were individually tested by trained researchers in a quiet room in their school. During each assessment, there were two 30-min sessions per child, utilising a mixture of different tasks to avoid fatigue. Testing was always performed during morning hours, and the order of the tasks was counterbalanced. At the end of each assessment, children received a small gift. The testing phase was in May-June, at the end of academic year.

\section{Materials}

Three different tasks tapping EF were included: In each trial of the Cognitive Flexibility task (e.g., Roebers and Kauer, 2009; Roebers, Röthlisberger, Cimeli, et al., 2011), two fish were presented simultaneously on a screen. Children were told that there were two families of fish (coloured and plain) and that they had to feed the two families consecutively by pressing the button on the side where the to-be-fed fish appeared. As the position of the to-be-fed fish was randomised, children had to change their response dimension for each trial and thus had to continuously update the relevant response dimension. The task contained 46 trials, with a short break in the middle; inter-stimuli intervals varied from 300 to $700 \mathrm{~ms}$. The percentage of accurate responses was used as the dependent variable. Split-half reliability was $r=.72$.

Inhibition. The second EF task was a Fruit-Stroop task (e.g., Archibald and Kerns, 1999) which contained four pages displaying 25 stimuli each. On the first page, four differently coloured squares were presented, and children were required to name the correct colour as quickly as possible. On the second page, four different fruits were presented in their original colours (congruent trial), followed by a third page displaying the same fruits in black and white. Children were then asked to name the original colours. The last page showed the fruits in incongruent colours (incongruent trial), and children had to name the original colours of the fruits. As introduced by Archibald and Kerns (1999), the dependent variable was the measure of interference, accounting for individual differences in time to task completion under lower inhibitory demands by subtracting the time to complete the task in the first pages from the time to complete the high interference trials (last two pages).

Working memory. The third EF task was the Backwards Colour Recall task (Roebers, Röthlisberger, Cimeli, et al., 2011), which is comparable to a classical backward digit recall task. Children were asked to memorise a sequence of differently coloured discs (1 second per item) and to recall the colours in reverse order. Testing started with a two-item sequence. Every time the child recalled at least two of three sequences with a particular length correctly, the sequence length was increased by one item. The number of correctly recalled sequences was used as a dependent variable.

Academic achievements. In the domains of mathematics and literacy, academic achievements were measured with standardised tests. Mathematical achievement was assessed by four subtests of the Heidelberger Rechentest (1-4; Haffner et al., 2005): Quantity Comparison, Equations, Sequences and Addition/Subtraction. Writing was assessed with a spelling task, in which children had to write down 22 words and read one sentence aloud. Reading was assessed with two tests (Würzburger Leise Lese Probe, Küspert and Schneider, 1998; Salzburger Lese-Screening, Mayringer and Wimmer, 2003), in which children were asked to judge the accuracy of a sentence or to search for a match meaning.

Intelligence was assessed by the classification subtest from the culture fair intelligence test - scale 1 (CFT-1; Cattell, Weiss and Osterland, 1997) at the first measurement point, and by the Test of Nonverbal Intelligence (TONI-3; Brown, Sherbenou and Johnsen, 1997) at measurement point two. 
Pre-academic self-concept and academic selfconcept. The scale we used was an adaptation of the scale first introduced by Nicholls (1978) and depicted a vertical row of schematic drawings of children. The children's task was to identify the one child in that row that best corresponded to his or her own performance. The scale was flexible in that different aspects of a child's self-concept could be assessed. In the present approach, we assessed self-concept in the domains 'letter knowledge', 'reading and writing of words', 'counting', 'arithmetic/calculating', 'solving puzzles' and 'playing memory'. The scale had good psychometric properties (Cimeli, Röthlisberger, Neuenschwander, et al., 2013) and correlated substantially with Harter and Picks' (1984) pictorial scale for measurement of pre-academic and academic self-concept in young children.

Teachers' ratings of cognitive self-regulation. A teacher questionnaire was developed within this study covering children's social, emotional, motivational and cognitive adaptation to school. Items were derived from the Intelligence and Development scale (Grob, Meyer and Hagmann-von Arx, 2009), the LOGIC study (Helmke, 1992) or were self-developed (Neuenschwander, Cimeli, Röthlisberger, et al., 2012). Items were rated on a 4-point Likert scale. From this item pool, two factors were extracted, one focusing on children's cognitive selfregulation ('the child forces himself to do a task even when he or she is tired') and the other focusing on their social integration ('the child has age-appropriate peer relations in class').

\section{Results}

Careful matching was done in order to create two subsamples of children who were comparable in terms of important background variables, such as gender distribution, age and non-verbal intelligence. Table 1 characterises the two resulting groups. Readers are reminded that the matching was done prospectively, that is, based on data at an early point of development. In other words, data were gathered from the children while they were attending the same play-oriented kindergarten classes, and no decision as to whether these children would graduate into special education classes or regular classes had been made at this point.

Table 1: Characteristics of the two subsamples of children BEFORE their transition into either special education or regular classes (means and standard deviations in parenthesis)

\begin{tabular}{|lcc|}
\hline & $\begin{array}{c}\text { later in special } \\
\text { education classes }\end{array}$ & $\begin{array}{c}\text { later in } \\
\text { regular classes }\end{array}$ \\
\hline \% of boys & 59 & 59 \\
Non-verbal intelligence & $13.7(5.5)$ & $14.4(4.2)$ \\
Age in months & $74.6(5.0)$ & $74.5(4.8)$ \\
Parental education & $4.5(1.9)$ & $5.4(2.4)$ \\
\hline
\end{tabular}

The same number of boys and girls were in the two groups, with boys (59\% in both groups) being somewhat overrepresented. An analysis of variance (ANOVA) was conducted to test for group differences in the matching variables. The results revealed that the matching was successful: there were no significant differences between the two groups in terms of non-verbal intelligence $(F(1,72)$ $=0.42$, n.s. $)$, age $(F(1,72)=0.002$, n.s. $)$ and parental education $(F(1,58)=2.13$, n.s $)$.

Next, the extent to which children differed from each other prior to their assignment to either the special education class or the regular class was explored. For this, multivariant ANOVAs were conducted and eta partial $^{2}$ - values were reported as estimators of effect sizes, allowing direct comparisons across the variables of interest (despite their different metrics). Table 2 presents the means and standard deviations (in parentheses) of the variables of interest for the present approach. The ANOVAs revealed strong differences between the two groups, always favouring those children who were later assigned by their teachers to regular classes. Children who later attended the special education classes were found to have substantially lower fine motor skills $(F(1,73)=18.43$, $P<.001)$ as well as poorer receptive and active language skills $(F(1,73)=20.19, P<.001)$. There were also significant group differences (favouring the children who were later found in the regular classes) in terms of academic self-concept $(F(1,73)=13.21, P<.001)$. Moreover, with respect to teacher's rating of students' cognitive self-regulatory skills $(F \quad(1,73)=22.24$, $P<.001)$ as well as teachers' ratings of their social integration in the class $(F(1,73)=10.11, P<.001)$, there were pronounced negative differences in those children later assigned to the special education classes. Surprisingly, no group differences were found with respect to children's EFs $(F(1,73)=0.80$, n.s $)$. As can be seen in the Table 2, effect sizes were largest for teachers' ratings of children's cognitive self-regulation and their fine motor

Table 2: Differences between the two groups of children BEFORE their transition into either special education or regular classes (means and standard deviations in parenthesis)

\begin{tabular}{|lccc|}
\hline & $\begin{array}{c}\text { later in special } \\
\text { education } \\
\text { classes }\end{array}$ & $\begin{array}{c}\text { later in } \\
\text { regular } \\
\text { classes }\end{array}$ & $\begin{array}{c}\text { Effect sizes } \\
\left.\text { partial eta }^{2}\right)\end{array}$ \\
\hline Fine motor skills & $23.5(6.4)$ & $29.1(4.7)$ & $.21^{* *}$ \\
Language skills & $84.8(13.7)$ & $98.3(11.8)$ & $.22^{* *}$ \\
Executive functions & $-0.05(.63)$ & $0.6(.41)$ & n.s. \\
$\quad(z$-scores) & $15.6(8.0)$ & $21.3(5.0)$ & $.16^{* *}$ \\
Academic self-concept & $2.6(0.4)$ & $3.1(.57)$ & $.24^{* *}$ \\
$\quad$ Teachers' ratings of & & & \\
cognitive self-regulation & $2.8(.69)$ & $3.3(.63)$ & $.16^{* *}$ \\
Social integration & & & \\
\hline
\end{tabular}

$* *=$ medium effect 
Table 3: Group differences between the two subgroups at the second measurement point -2 years later - in terms of academic achievement (means and standard deviations in parenthesis)

\begin{tabular}{|lccc|}
\hline & $\begin{array}{c}\text { now in special } \\
\text { education } \\
\text { classes }\end{array}$ & $\begin{array}{c}\text { now in } \\
\text { regular } \\
\text { classes }\end{array}$ & $\begin{array}{c}\text { Effect } \\
\text { sizes } \\
\left(\text { partial eta }^{2}\right)\end{array}$ \\
\hline Mathematics & $12.4(6.5)$ & $17.5(5.9)$ & $.15^{* *}$ \\
Equations & $7.6(3.5)$ & $10.5(3.4)$ & $.16^{* *}$ \\
Sequences & $4.5(2.4)$ & $7.1(2.7)$ & $.20^{* *}$ \\
Addition/subtraction & & & $.09^{*}$ \\
Literacy & $42.9(20.4)$ & $56.6(23.9)$ & $.08^{*}$ \\
Reading speed & $12.2(.7)$ & $18.0(11.3)$ & $.14^{* *}$ \\
Reading Comprehension & $10.5(4.4)$ & $13.5(3.4)$ & \\
Spelling & & & \\
\hline
\end{tabular}

Note: ${ }^{1}$ No of correctly spelled words $(\max =22)$.

$*=$ small effect

$* *=$ medium effect

and language skills. As an aside, while $38 \%$ of children in the special education classes were immigrants, only $9 \%$ of the children from our matched sample that later attended regular classes were immigrants.

Next, we wanted to explore children's academic performance and self-concept as a function of school context. Children assigned to the two schooling contexts differed strongly in terms of academic achievement. Table 3 provides an overview of the children's academic achievement in the domains of mathematics and literacy, respectively. Multivariate ANOVAs (MANOVAs) were conducted to assess the differences. As can be seen from Table 3, children in the special education classes performed substantially poorer on all three subtests of mathematics compared to children in the matched groups in regular classes. Substantial group differences were found in terms of Equations $(F(1,73)=12.23, P<.001)$, Sequences $(F(1,73)=13.42, P<.001)$ and Additions/ subtractions $(F(1,73)=17.41, P<.001)$.

As to literacy, a similar pattern of results was found, although the group differences favouring the children in the regular classes were somewhat less pronounced. There was a significant group difference when students' reading speed was considered $(F(1,72)=7.04, P<.001)$, when reading comprehension was considered $(F(1,72)=6.06$, $P<.001)$ and also for spelling $(F(1,73)=11.00$, $P<.001)$.

Finally, we wanted to explore children's school adjustment and their developmental progression with respect to EF, fine motor skills, language and self-concept. Table 4 presents the means and standard deviations of the variables of interest. It can be seen that the two groups of children differed in most of the variables, with the only exception being social integration (see below). Fine motor skills, EF and academic self-concept were measured
Table 4: Differences between the two groups of children 2 years AFTER their transition into either special education or regular classes (means and standard deviations in parenthesis)

\begin{tabular}{|lccc|}
\hline & $\begin{array}{c}\text { now in special } \\
\text { education } \\
\text { classes }\end{array}$ & $\begin{array}{c}\text { now in } \\
\text { regular } \\
\text { classes }\end{array}$ & $\begin{array}{c}\text { Effect sizes } \\
\left(\text { partial eta }{ }^{2}\right)\end{array}$ \\
\hline Fine motor skills & $23.4(6.9)$ & $27.3(5.8)$ & $.08^{*}$ \\
Executive functions & $-0.42(.84)$ & $.05(.72)$ & $.06^{*}$ \\
$\quad(z$-scores $)$ & $20.1(3.3)$ & $21.5(2.7)$ & $.05^{*}$ \\
Academic self-concept & $2.5(.68)$ & $2.9(.74)$ & $.05^{*}$ \\
Teachers` ratings of & & & \\
$\quad$ cognitive self-regulation & $3.2(.69)$ & $3.3(.70)$ & n.s. \\
Social integration & & & \\
\hline
\end{tabular}

$*=$ small effect

$* *=$ medium effect

identically or nearly identically at the first and second measurement points. To investigate whether children underwent a differential developmental trajectory in the 2 years between the two measurement points, a MANOVA was conducted, with the first (t1) versus second ( $t 2)$ measurement as the within-subject factor and class as the between-subject factor. For both fine motor skills and EF, there were no interactions between group and time, indicating that both groups of children underwent approximately the same developmental course in the two different learning contexts $(F \mathrm{~s}<1$, n.s.). At the same time, for both fine motor skills $(F(1,72)=6.25$, $P<.001)$ and $\mathrm{EF}(F(1,72)=4.12, P<.001)$, there were substantial group differences favouring the children in the regular classes. Such a mixed model ANOVA was conducted on students' academic self-concept with group (special education versus regular classes) as the betweensubject factor and time as the within-subject factor. The results revealed a strong group effect $(F(1,72)=14.8$, $P<.001$, eta $\left.^{2}=.17\right)$ as well as a significant effect of time $\left(F(1,72)=8.78, P<.001\right.$, eta $\left.{ }^{2}=0.11\right)$. These two main effects were modified by a significant interaction between group and time $(F(1,72)=7.31)$. Follow-up analyses on this interaction revealed that while the children in the special education classes improved significantly in terms of their academic self-concept (from $M=15.6$ at t1 to $M=20.1$ at t2), the academic self-concept of the children in the regular classes remained about the same $(M=21.3$ and 21.5 at $\mathrm{t} 1$ and $\mathrm{t} 2$, respectively).

The children had all made the transition from Kindergarten to school between the first and second measurement points. Thus, teachers' ratings of the children's selfregulatory skills and their social integration should not be analysed longitudinally. Interestingly, while the two groups differed strongly with respect to both aspects of teachers' ratings while all children were still in kindergarten, at the second measurement point, children from the two groups differed only with respect to their 
cognitive self-regulation $(F(1,72)=3.62, P<.001)$, but not with respect to their social integration $(F$ (1, 72) $=0.44$, n.s)

\section{Discussion}

Our longitudinal study investigated differences in children's academic performance and their developmental progression in central aspects of school readiness as a function of school context. Two groups of children were matched to each other on important background variables. There were two measurement points for the children: in Kindergarten at the age of 5 before the start of school and their assignment to either school setting, and after 2 years of schooling in special education or regular classes.

Our study revealed interesting results in terms of which characteristics seem to be important for Kindergarten teachers to assign children to a special education class: children assigned to special education classes had substantially poorer language and fine motor skills and lower pre-academic self-concept prior to the start of school. Teachers rated these children as having disadvantages in their cognitive self-regulatory skills and social integration. However, almost every fourth child in the special education classes was an immigrant, thus having another mother tongue, but only $9 \%$ of the children in this sample who later attended regular classes were immigrants. Surprisingly, before the transition to school, no differences between children were found in EF such as cognitive flexibility, WM and inhibition. Research suggests a central role of EF for children's cognitive and social development. It is known that EF play a central role in promoting school readiness and predict later academic outcomes and school success. These results can be interpreted as showing that the children assigned to special education classes were underachieving; they were functioning less than optimally in group settings, although their cognitive development was normal.

One major aim of the present study was to assess whether children in special education classes benefit from this school setting and were able to catch up in their development as intended. After 2 years of schooling, however, children assigned to the two different educational contexts differed significantly in terms of academic achievement. Pupils in special education classes performed substantially poorer in mathematics and literacy. They were also poorer in measurements of EF, academic self-concept and as rated by the teachers, in their cognitive self-regulatory skills. Thus, assigning children to special education classrooms hindered more pronounced cognitive improvements within a predictable range, in contrast to the comparable group of children attending regular classes.

The only exceptions were in academic self-concept and teachers' ratings of social integration, which special education classes seemed to support during this 2-year period. Thus, special education classes improved children's academic self-concept, whereas their peers in regular classes remained at the same level for 2 years. In regard to teachers' ratings of social integration, there were also improvements in favour of the special education classes; however, these results cannot be evaluated longitudinally because there were different teachers in Kindergarten and school, and the teachers in the special education classes had another frame of reference for their ratings (only children in special education). Notably, both groups of children underwent approximately the same developmental course in the two different learning contexts. A limitation in our study is that we did not have a measurement for social integration which would have been possible to use longitudinally.

\section{What were the factors for having special education status?}

Children assigned later to special education showed no group differences in EF, but before starting school they were substantially poorer in their receptive and active language skills. Poor language skills might be a sign of language delays or deficits (Bishop and Snowling, 2004). Poor language skills have been also found to be a reason for a child's special education status (Takala, Pirttimaa and Törmänen, 2009). In addition to the role of language in enabling children's functioning in the group and participating in social interaction, language skills have been found to influence children's academic self-concept (Huang and Snedeker, 2011).

There is increasing interest in the role of language in EF in developmental disorders. It is known (Joseph and Tager-Flusberg, 2004) that disorders in language skills and EF coexist in a variety of disorders and interact across development. However, the children in our study did not show deficits in EF before school placement. After 2 years of education, the development of EF differed between children who were in special education classes compared to their peers in regular classes. Positive development was observed with children in regular classes, i.e. in inclusive setting.

Klenberg (2015) highlighted the problems of evaluating $\mathrm{EF}$ in different conditions. Behavioural evaluation and teachers' perceptions in school situations might differ from individual assessments and measurements of $\mathrm{EF}$ in clinical settings. A solution might be to use both behavioural evaluations and psychological measurements; however, more important is multidisciplinary collaboration between professionals when evaluating a child's situation as well as continuing education for those professionals. As a limitation to this study it can be stated that EF was assessed only in school situation.

In our study, $38 \%$ of the children in the special education classes were immigrants compared to $9 \%$ in regular classes. Thus, children's immigrant background may influence their language skills or their school placement 
in general. In some studies, pupils with immigrant backgrounds and SEN have been found to be categorised by ethnicity, language, culture and religion (e.g., Paavola, 2007). However, it might be interpreted that there is an intention to assign a child to a context where he or she can catch up with age-appropriate language skills and become familiarised with the educational system. Teachers rated children who will be in special education classes as having disadvantages in their social integration in the class. Poor language skills can affect children's peer relations. Together with their immigrant backgrounds, children might feel like outsiders.

Our study raises the question of what background factors should be taken into account when planning educational processes for children with SEN. Evaluation of EF should be a central part of such processes, as they are known to be an important aspect of school readiness.

\section{Does special education improve cognitive development} and academic achievements?

After 2 years of education in two schooling contexts, there were significant differences in terms of academic achievements. In the domains of mathematics and literacy, children in the special education classes performed substantially poorer in all three subtests of mathematics (equations, sequences, additions/subtractions) compared to the matched groups in regular classes. In literacy skills, significant group differences were found in reading speed, reading comprehension and spelling. These results suggest that children learn at a slower pace in these classes, or, stated in another way, children in regular classes benefit from the learning pace and their higher performing classmates.

What is the role of special education? Keeping in mind the essential role of EF in cognitive development, it can be argued that the aims and curricula in special education classes have been too modest and lacking in proper goaldirected instructions - the principle ideas of inclusion.

Is it possible that deficits in language and fine motor skills are so overarching and permanent that they affect positive cognitive processing and development? In general, cognitive interventions have been found to be effective in early education, and they have important transfer effects in terms of academic success (e.g., Barnett, 2011). Special education should utilise a large variety of different interventions to enhance children's academic achievement and socio-emotional skills. Adey, Csapo, Demetriou, et al. (2007) explored the nature of general cognitive ability and found it to be modifiable through education and intervention. In their theory of cognitive organisation and development, Demetriou, Spanoudis and Mouyi (2011) included a guideline for educating children to achieve their capacities and use their skills effectively. General thinking, reasoning skills, and the measured learning-related attitudes, are partially outcomes of education, and they can be enhanced with both high-quality basic education and specific interventions (e.g., Kuusela, 2002).

Do special education classes support children's academic self-concept?

In our study, children in special education classes improved their academic self-concept significantly compared to children in regular classes, who showed little change. The diversity within special education classes is high compared to regular classes, and the curricula in special education classes usually emphasises the learning of academic skills using individualised education, varied learning instruction and creating a positive and supportive atmosphere and learning environment. All these conditions are needed in inclusive special education. Baird, Scott, Dearing, et al. (2009) found that students with learning disabilities were more likely to possess low academic self-efficacy and to believe that intelligence was fixed and nonmalleable and that performance was more important than learning goals, and they interpreted the exertion as showing limited levels of ability. The results of our study suggest that teachers were successful in creating this positive learning atmosphere, and children benefitted from it in terms of their self-concept. The enhancement in self-concept might also be due to the frame of reference: in the special education classrooms, poorer performing children compared themselves with other poorly performing children, increasing the likelihood of positive self-evaluations. Whether or not such positive effects on children's self-concept can spill over to positive effects on academic achievement - and whether or not they are maintained when children are reintegrated into regular classes - is an open but important question (Elbaum, 2002).

\section{Conclusion}

In conclusion, our results showed that children with SEN who were receiving their education in special education classes did not experience similar cognitive development as their matched peers in regular classes. In Kindergarten, their EF was on the same level, but the groups differed after 2 years. In addition, the children in special education classes demonstrated poorer academic achievement after 2 years of schooling. EF seems to be sensitive to the demands of the learning context, and thus the educational context might hinder the developmental progression. It can be concluded that inclusive education supports children with SEN more than segregative special education classes.

Defining children with SEN requires analytic evaluation, which needs to cover measurements of cognitive processes and behavioural evaluations. Defining SEN in developing children is a challenge. Early identification has been a major issue in educational research targeting early interventions and the prevention of future problems. When categorising children with SEN, Norwich (2006, p. 
56) found different factors for determination: (1) patterns of exceptional child functioning relevant to education, (2) underlying disabilities or impairments relevant to child functioning in education, (3) kinds of replacement and general provision and (4) kinds of curriculum design and content and teaching strategies. Successful education should create a learning environment that supports not only the cognitive abilities of all children but also their academic skills and socio-emotional development.

Address for correspondence

Minna R.K. Törmänen,

Teacher Education,

Faculty of Educational Sciences,

University of Helsinki,

Siltavuorenpenger 3A, PO Box 9, 00014,

Finland.

Email: minna.tormanen@helsinki.fi.

\section{References}

Adey, P., Csapo, B., Demetriou, A., Hautamaki, J. \& Shayera, M. (2007) 'Can we be intelligent about intelligence? Why education needs the concept of plastic general ability.' Educational Research Review, 2, pp. 75-97.

Ainscow, M. (2005) 'Developing inclusive education systems: what are the levers for change?' Journal of Educational Change, 6, pp. 109-24.

Ainscow, M. \& Miles, S. (2009) Developing Inclusive Education Systems: How Can We Move Policies Forward?. Mancester: University of Manchester.

Archibald, S. \& Kerns, K. (1999) 'Identification and description of new tests of executive functioning in children.' Child Neuropsychology, 5, pp. 115-29.

Aunola, K., Leskinen, E., Onatsu-Arvilommi, T. \& Nurmi, J. (2002) "Three methods for studying developmental change: a case of reading skills and self-concept.' British Journal of Educational Psychology, 72, pp. 343-64.

Baird, G., Scott, W., Dearing, E. \& Hamill, S. (2009) 'Academic self-efficacy, theories of intelligence, learning vs. performance, goal preferences, and effort attributions.' Journal of Social and Clinical Psychology, 28 (7), pp. 881-908.

Barnett, W. S. (2011) 'Effectiveness of early educational intervention.' Science, 333 (6045), pp. 975-8.

Best, J. \& Miller, P. (2010) 'A developmental perspective on executive function.' Child Development, 81, pp. 1641-60.

Bishop, D. \& Snowling, M. (2004) 'Developmental dyslexia and specific language impairment: same or different?' Psychological Bulletin, 130 (6), pp. 858-88.

Bjorklund, D. \& Bering, J. (2002) 'The evolved child: applying evolutionary developmental psychology to modern schooling.' Learning and Individual Differences, 12, pp. 3473.

Blair, C. (2002) 'School readiness: integrating cognition and emotion in a neurobiological conceptualization of children's functioning at school entry.' American Psychologist, 57, pp. 111-27.

Blair, C. \& Raver, C. (2015) 'School readiness and selfregulation: a developmental psychobiological approach.' Annual Review of Psychology, 66, pp. 711-31.

Brown, L., Sherbenou, R. \& Johnsen, S. (1997) TONI-3: Test of Nonverbal Intelligence. (3rd edn). Austin, TX: Pro-Ed.

Buckner, J., Mezzacappa, E. \& Beardslee, W. (2003) 'Characteristics of resilient youths living in poverty: the role of self-regulatory processes.' Development and Psychopathology, 15, pp. 139-62.

Buysse, V., Goldman, B. D. \& Skinner, M. (2002) 'Setting effects on friendship formation among young children with and without disabilities.' Exceptional Children, 68, pp. 503-17.

Cattell, R., Weiss, R. \& Osterland, J. (1997) CFT 1: Grundintelligenztest Skala 1 (5. Aufl.) [German Version of the Culture Fair Intelligence Test, Scale 1]. Göttingen, Germany: Hogrefe.

Cimeli, P., Röthlisberger, M., Neuenschwander, R. \& Roebers, C. (2013) 'Stellt ein niedriges Selbstkonzept einen Risikofaktor für Anpassungsprobleme nach dem Schuleintritt dar?' Kindheit und Entwicklung, 22 (2), pp. 105-12.

D’Amico, A. \& Passolunghi, M. (2009) 'Naming speed and effortful and automatic inhibition in children with arithmetic learning disabilities.' Learning and Individual Differences, 19 (2), pp. 170-80.

Demetriou, A., Spanoudis, G. \& Mouyi, A. (2011) 'Educating the developing mind: towards an overarching paradigm.' Educational Psychology Review, 23 (4), pp. 601-63.

Diamond, A. (2006) 'The early development of executive functions.' In E. Bialstock \& F. Craik (eds), The Early Development of Executive Functions: Lifespan Cognition: Mechanisms of Change, pp. 70-95. Oxford: Oxford University Press.

Diamond, A. (2013) 'Executive functions.' Annual Review of Psychology, 64, pp. 135-68.

Elbaum, B. (2002) 'The self-concept of students with learning disabilities: a meta-analysis of comparisons across different placements.' Learning Disabilities Research and Practice, 17, pp. 216-26.

Fuchs, D. \& Fuchs, L. (2006) 'Introduction to response to intervention: what, why, and how valid is it?' Reading Research Quarterly, 41 (1), pp. 93-9.

Gilliam, W. \& Shahar, G. (2006) 'Preschool and child care expulsion and suspension: rates and predictors in one state.' Infants \& Young Children, 19 (3), pp. 228-45.

Grob, A., Meyer, C. S. \& Hagmann-von Arx, P. (2009) Intelligence and Development Scales (IDS). Bern: Hans Huber. 
Guay, F., Marsh, H. \& Boivin, M. (2003) 'Academic self-concept and academic achievement: developmental perspectives on their causal ordering.' Journal of Educational Psychology, 95 (1), pp. 124-36.

Haffner, J., Baro, K., Parzer, P. \& Resch, F. (2005) Heidelberger Rechentest (HRT 1-4). Göttingen, Germany: Hogrefe.

Harter, S. \& Pike, R. (1984) The Pictorial Scale of Perceived Competence and Social Acceptance for Young Children, Child Development, 55(6), pp. 19691982.

Helmke, A. (1992) Self-concept of aptitude, achievement-related motives, and attitudes of second graders. In F. E. Weinert \& W. Schneider (eds), The Munich Longitudinal Study of Genesis of Individual Competencies (LOGIC): Assessment procedures and results of Wave Five, pp. 82-105. Munich, Germany: Max-Planck-Institute of Psychological Research.

Henry, L. (2001) 'How does the severity of a learning disability affect working memory performance?' Memory, 9, pp. 233-47.

Huang, Y. \& Snedeker, J. (2011) 'Logic and conversation revisited: evidence for a division between semantic and pragmatic content in real time language comprehension.' Language and Cognitive Processes, 26 (8), pp. 1161-72.

Hughes, C. \& Graham, A. (2002) 'Measuring executive functions in childhood: problems and solutions?' Child and Adolescent Mental Health, 7, pp. 131-42.

Huizinga, M., Dolan, C. \& van der Molen, M. (2006) 'Age-related change in executive function: developmental trends and a latent variable analysis.' Neuropsychologia, 44, pp. 2017-36.

Joseph, R. M. \& Tager-Flusberg, H. (2004) The relationship of theory of mind and executive functions to symptom type and severity in children with autism. Developmental and Psychopatology, 16 (1), pp. 137155.

Klenberg, L. (2015) Assessment and Development of Executive Functions in School-Age Children. Unpublished doctoral dissertation, Faculty of Behavioural Sciences, Institute of Behavioural Sciences, University of Helsinki.

Klenberg, L., Korkman, M. \& Lahti-Nuuttila, P. (2001) 'Differential development of attention and executive functions in 3- to 12-year-old Finnish children.' Developmental Neuropsychology, 20, pp. 407-28.

Küspert, P. \& Schneider, W. (1998) Würzburger Leise Leseprobe [Würzburger's Reading Test]. Göttingen, Germany: Hogrefe.

Kuusela, J. (2002) Helsingin koulujen oppimistulokset: kokoava katsaus [Learning Results in Helsinki Schools: Summarizing Survey]. Unpublished research report, National Board of Education.

Liebermann, D., Giesbrecht, G. \& Muller, U. (2007) 'Cognitive and emotional aspects of self-regulation in pre-schoolers.' Cognitive Development, 22, pp. 51129.

Lyons, K. \& Zelazo, P. (2011) 'Monitoring, metacognition, and executive function: elucidating the role of self-reflection in the development of selfregulation.' Advances in Child Developmental Behavior, 40, pp. 379-412.

Markussen, E. (2004) 'Special education: does it help? A study of special education in Norwegian upper secondary schools.' European Journal of Special Needs Education, 19, pp. 33-48.

Mayringer, H. \& Wimmer, H. (2003) SLS 1-4. Salzburger Lese-Screening für die Klassenstufen 1-4. [Salzburger's Reading-Screening for 1st to 4th graders]. Bern, Switzerland: Hans Huber.

Moffitt, T., Arseneault, L., Belsky, D., Dickson, N., Hancox, R. J., Harrington, H. \& Caspi, A. (2011) 'A gradient of childhood self-control predicts health, wealth, and public safety.' Proceedings of the National Academy of Sciences of the United States of America, 108, pp. 2693-8.

Neuenschwander, R., Cimeli, P., Röthlisberger, M. \& Roebers, C. (2012) 'How do different aspects of selfregulation predict successful adaptation to school?' Journal of Experimental Child Psychology, 113, pp. 353-71.

Nicholls, J. (1978) 'The development of the concepts of effort and ability, perception of own attainment, and the understandingthat difficult tasks require more ability.' Child Development, 49, pp. 800-14.

Norwich, B. (2006) 'Categories of special education needs.' In L. Florian (ed), The SAGE Handbook of Special Education, pp. 55-66. London: Sage.

Paavola, H. (2007) Monikulttuurisuuskasvatus päiväkodin monikulttuurisessa esiopetusryhmässä [Multicultural Education in a Multicultural Kindergarten Pre-School Group]. PhD dissertation, University of Helsinki.

Rafferty, Y., Piscitelli, V. \& Boettcher, C. (2003) 'The impact of inclusion on language development and social competence among preschoolers with disabilities.' Exceptional Children, 69, pp. 467-79.

Rea, P., McLaughlin, V. \& Walther-Thomas, C. (2002) 'Outcomes for students with learning disabilities in inclusive and pull-out programs.' Exceptional Children, 72, pp. 203-22.

Riggs, N., Blair, C. \& Greenberg, M. (2003) 'Concurrent and 2-year longitudinal relations between executive function and the behaviour of 1st and 2 nd grade children.' Child Neuropsychology, 9, pp. 267-76.

Roebers, C., Cimeli, P., Röthlisberger, M. \& Neuenschwander, R. (2012) 'Executive functioning, metacognition, and self-perceived competence in elementary school children: an explorative study on their interrelations and their role for school achievement.' Metacognition and Learning, 7 (3), pp. 151-73.

Roebers, C. \& Kauer, M. (2009) 'Motor and cognitive control in a normative sample of 7-year-olds.' Developmental Science, 12, pp. 175-81. 
Roebers, C. M., Röthlisberger, M., Cimeli, P., Michel, E. \& Neuenschwander, R. (2011) 'School enrolment and executive functioning: a longitudinal perspective on developmental changes, the influence of learning context, and the prediction of pre-academic skills.' The European Journal of Developmental Psychology, 8 (5), pp. 526-40.

Schmidt, M. \& Čagran, B. (2008) 'Self-concept of students in inclusive settings.' International Journal of Special Education, 23, p. 1.

Schwab, S., Gebhardt, M., Krammera, M. \& GasteigerKlicpera, B. (2014) "Linking self-rated social inclusion to social behaviour. An empirical study of students with and without special education needs in secondary schools.' Eurppean Journal of Special Needs Education, 30 (1), pp. 1-14.

Spinath, B. \& Spinath, F. (2005) 'Development of selfperceived ability in elementary school: the role of parents' perceptions, teacher evaluations, and intelligence.' Cognitive Development, 20 (2), pp. 90204.
Takala, M., Pirttimaa, R. \& Törmänen, M. (2009) 'Inclusive special education: the role of special education teachers in Finland.' British Journal of Special Education, 36 (3), pp. $162-72$.

Terzi, L. (2005) 'Beyond the dilemma of difference: the capability approach to disability and special educational needs.' Journal of Philosophy of Education, 39, p. 3.

UNESCO (1994) The Salamanca Statement and Framework for Action on Special Needs Education. Paris: UNESCO.

Wang, H. (2009) 'Should all students with special educational needs (SEN) be included in mainstream education provision? - A critical analysis.' International Education Studies, 2, p. 4.

Welsh, J., Nix, R., Blair, C., Bierman, K. \& Nelson, K. (2010) 'The development of cognitive skills and gains in academic school readiness for children from low income families.' Journal of Educational Psychology, 102, pp. 43-53. 